\title{
Spider Bites Might Present as Cellulitis Like in Early Cases and Pyoderma Gangrenosum Like in Late Cases
}

\author{
(1) Khalifa E. Sharquie', (1) Raed I. Jabbar ${ }^{2}$ \\ 1University of Baghdad Medical City Teaching Hospital, College of Medicine, Department of Dermatology, Baghdad, Iraq \\ 2Fallujah Teaching Hospital, Al-Anbar Health Directorate, Department of Dermatology, Fallujah, Iraq
}

\section{ABSTRACT}

Background: Spiders are blamed for all kinds of things that turn out to be simple infections or some other bugs faults as most are harmless bite except two spiders, the black widow and brown recluse that might cause reaction locally as ulcers and systemic beyond the bite like abdominal pain, cramps or respiratory problems.

Materials and Methods: Twenty-four patients with history of spider bite were recorded during the period from May 2012 to March 2020 , their ages ranged from 25-35 years five females and 19 males. All cases were seen three-15 days after biting and no one examined at the time of bite. On careful questioning of patients, many had seen brown-black spider while others had felt a bite only.

Results: On careful examination, the lesional bites could be divided into early and late presentations. Regarding the early presentation in six cases were observed and all had cellulitis like picture with small black necrosis at the center while the late cases showed gangrenous well defined ulcer that simulate pyoderma gangrenosum in (18) patients and these ulcers were characteristically polygonal in shapes at their margins. The sites of these bites were as follow: 14 (58.3\%) thighs including groins, 3 (12.5\%) legs, 3 (12.5\%) fingers, 3 (12.5\%) male genitalia and one (4.16\%) was left axilla. Medical management including topical antiseptic together with topical and oral antibiotic cover with oral antihistamine and oral prednisolone. The duration of therapy depending on the size of ulcer but generally it took from two weeks to two months. No surgical debridement was carried out.

Conclusion: Spider bites are commonly seen adult males and could be presented as early cellulitis like and late polygonal pyoderma gangrenosum like. The commonest sites affected were lower limbs, most commonly thighs and groins. Healing might take few weeks to few months depending on the size of necrotic ulcer. Wound debridement was not carried out but skin grafting might be suggested for large ulcer as to reduce the time of morbidity and recovery.

Keywords: Spider bite, Pyoderma gangrenosum, Ulcer

\section{Introduction}

Spiders are carnivorous members of the animal kingdom that use webs and venom to capture and kill prey. Within the united states, 3 genera contain species whose bites are toxic to man: (a) Latrodectus (b), Loxosceles, and (c) Tegenaria [1].
Latrodectus: Latrodectus genus, or widow spiders, are frequently black in color and own a red, hourglass shaped marking on their abdomen. Females are larger than males. It is the most substantial venomous spider in North America and Australia [2,3]. Its venom is alpha-latrotoxin which results in the exocytosis of synaptic vesicles from parasympathetic endings due to the excitation of 
calcium-dependent mechanisms, releasing acetylcholine and catecholamines [4].

The symptoms that caused by the bite of this spider are called latrodectism. The pain from its bite is same of a pinprick and the skin reaction is similar to the target lesion that can be observed in the site of biting [5]. Latrodectism starts within few minutes with the development of pain throughout the whole body and symptoms such as emesis, respiratory failure, delirium, partial paralysis of limbs, abdominal muscle cramps, hypertension, pyrexia, fasciculation and muscle spasm are developed within a few hours [6]. Symptoms may be misdiagnosed as acute abdomen. Mortality result from biting is less than $1 \%$. Bites commonly occur during warm seasons [7].

Until 2012 there was no any study mentioned the presence of black widow spider in Iraq, after that Al-Iraqi and Nayef, 2012 recorded two species of black widow spiders for the first time in Mosul city (Iraq) during the summer of 2012 and 2013 [8]. Also two females of the red-back spider, Latrodectus scelio Thorell, 1870 were first recorded in Baghdad (Iraq) in 2012 [9].

These spiders weren't existing in the Iraqi environment prior the American occupation to Iraq but they may be introduced unintentionally to Iraq with equipments, goods, and containers that occupation forces fetched with them to Iraq [8].

Loxosceles: Loxosceles spiders are found throughout the world. The brown recluse spider ( $\mathrm{L}$ reclusa) is tan to brown and has a violinshaped mark on its back. It has long legs, short body hair, and three couples of eyes [10]. It favors dry, filthy, undisturbed places with good cover such as lofts and storage areas indoors and cowsheds and woodpiles outdoors. Females are more common, are slightly bigger, and inject more venom when they bite [11]. This type of spider was not reported in Iraq but their presence was recorded after 2012 through web sites but not through a study [12].

The venom contains alkaline phosphatase [13], 5' ribonucleotide, hyaluronidase, esterase [14], sphingomyelinase D2, which is the most important one [15]. Hyaluronidase possibly the cause for gravity-dependent lesional spread [16]. Stomach enzymes comprising protease, lipase and hydrolase may go with venom. Lipase is responsible for depressed scarring of lesions, conspicuous above fatty sites [17].

There are two important clinical types of loxoscelism: necrotic cutaneous and viscerocutaneous loxoscelism [18].

The clinical manifestations depend on the age and general health of the patient, the quantity of venom introduced and the location of the bite-fatty areas such as the proximal thigh and the buttocks show further cutaneous reaction and broad involvement of the whole subcutaneous layer [18].
In necrotic cutaneous loxoscelism, there is local damage to the skin and subcutaneous tissues, but systemic symptoms are mild. The bite of the spider is usually relatively painless. However, after a period of minutes or hours, intense pain occurs at the site, accompanied by erythema, oedema and a central vesicle or bulla. In severe envenomation, a 'target' lesion develops - within 12 to 24 hours the lesion may become hemorrhagic, and the characteristic "red, white, and blue sign," consisting of erythema, ischemia, and thrombosis is seen. After three or four days, the central area becomes necrotic, and an eschar develops. The eschar is finally shed, leaving an ulcer, which may take an abundant time to heal [18]. Eventually deep ulcers develop. The bite reaction may cause an ulcer resemble pyoderma gangrenosum [1].

In viscerocutaneous or systemic loxoscelism, general symptoms of fever, malaise, restlessness and headache are noticeable. Within $24 \mathrm{~h}$ of the onset of general symptoms, ecchymoses, jaundice, haematuria and haemoglobinuria suggest great intravascular haemolysis, which may lead to acute renal failure and death [1].

Most cases of recluse spider bites are recorded in the hot months when the spider becomes very active; it ordinarily prone to bite when the patient is either sleeping or wear clothes. These spiders appear to have a preference to bite on the trunk, thigh or arms, and the thigh is the commonest site $[19,20]$. In rare occasions, bites from brown recluse spiders can cause clinically important dermal necrosis and subsequent scarring [21]. Wound chronicity and pyoderma gangrenosum occur rarely this may be due to an unusually severe allergic reaction [22]. Slow healing inflammatory Loxosceles spider bite ulcers may become pyoderma gangrenosum due to sever immunologic abnormalities or Chlamydia pneumoniae infection [23].

Tegenaria: Tegenaria agrestis, the hobo spider, is the main cause of necrotic arachnidism in the Pacific Northwest of United States and can be found in a region extending from Alkasa to Utah. The local cutaneous effects after hobo spider, which can ranged from mild to serious, are similar to those produced by the brown recluse [1].

Armadeiras (Armed Spiders): They have long arms. As they usually hide in banana boxes, they are known as banana bunch spiders by locals. Its bite result in intense pain which is noticed in about 96\% of patients [24]. The bite of this spider may cause respiratory failure and death [4].

Tarantula: Tarantulas are large hairy spiders common in the southwestern US, and kindred species are presented throughout the world. Tarantula is characterized by its hairy 3-inch brown or black colored body. Itching at the site of urticating hair penetration is the most common skin manifestation and may last for several weeks after exposure [4]. 
In Iraq, these cases of spider bites are not reported among people but after 2012, patients were seen with picture similar to rash that induced by brown recluse spider. Also, there was no report of presence of both brown recluse and black widow spiders in Iraq and neighboring countries like Iran and Turkey [25] but after 2012, cases were reported from now and then.

So the objective of present work is to report these spider bites for the first time and to do full clinical description of spider bites that had been seen during the period from 2012-2020.

\section{Materials and Methods}

Twenty-four patients with history of spider bites were seen during the period from May 2012 to March 2020, their ages ranged from $25-35$ years with a mean of 27 year, with five (20.83\%) females and 19 (79\%) males.

The diagnosis was supported by history and clinical appearance and confirmed if the patient fetched the spider. All cases were seen around three to 15 days after biting.

Satisfying history was taken from each patient included: age, sex, duration of the bites, associated sign and symptoms and past medical history.

Clinical examination was done including the site and clinical appearance of the bite.

A full investigations were carried out included: complete blood count, blood urea and serum creatinine.

No systemic manifestations like nausea, vomiting and hypertension were mentioned by patients at the time of spider bite.

This study followed the Declaration of Helsinki Principles and permission was taken from each patient before photograph. Also, no intervention was done for any patient.

Treatment of the bite and ulcer was conservative using medical therapy and surgical debridement was not advised.

\section{Statistical Analysis}

Data were statistically described in terms of rang, mean, frequencies (no. of cases), disease duration and male to female ratio. All statistical calculation were done using Statistical Package for the Social Sciences version 20.

\section{Results}

On careful examination, the lesional bites could be divided into early and late presentations. Regarding the early presentation six (25\%) cases were observed during 3-15 days after bite and all had cellulitis like picture seen as erythematous plaques with small central necrosis at the center (Figures 1,2). While the late cases seen in 18 (75\%) patients in around 10 days after biting and showed gangrenous well defined ulcers of variable in size and simulated pyoderma gangrenosum. These ulcers were characteristically polygonal at their margins with well-defined in shapes and covered by thick black eschar which was difficult to be removed by forceps. The sites of these bites were as follow: 14 (58.3\%) thighs including groins (Figures 3, 4), three (12.5\%) legs, three fingers (12.5\%) and three (12.5\%) male genitalia (Figure 5) and one (4.16\%) was left axilla.

The results of all investigations done by patients were normal.

Medical management including topical antiseptic together with topical and oral antibiotic cover with oral antihistamine and oral prednisolone. The duration of therapy depending on the size of ulcer but generally it took from two weeks to two months. No surgical debridement was carried in any patient.

\section{Discussion}

There are two spiders that have been reported to cause skin manifestation as results of their bites. These are brown recluse and black widow spiders which are seen all over the world but most common in United States and Australia [1].

These two spiders were not reported in Iraq and neighboring countries like Iran and Turkey [25] but after American occupation of Iraq in 2003, these spiders were suspected to be present as results of seeing of strange cases of skin bites and these were increased in their frequency after 2013. Since then these spiders where documented to be present in Iraq both the black and brown spider $[8,9,12]$. And as all reported cases presented with spider bites rather than with systemic manifestations, we can assume that this skin problem is caused by brown rather than black spiders. This in agreement with other study where the causative spider is rarely seen for identification [26].

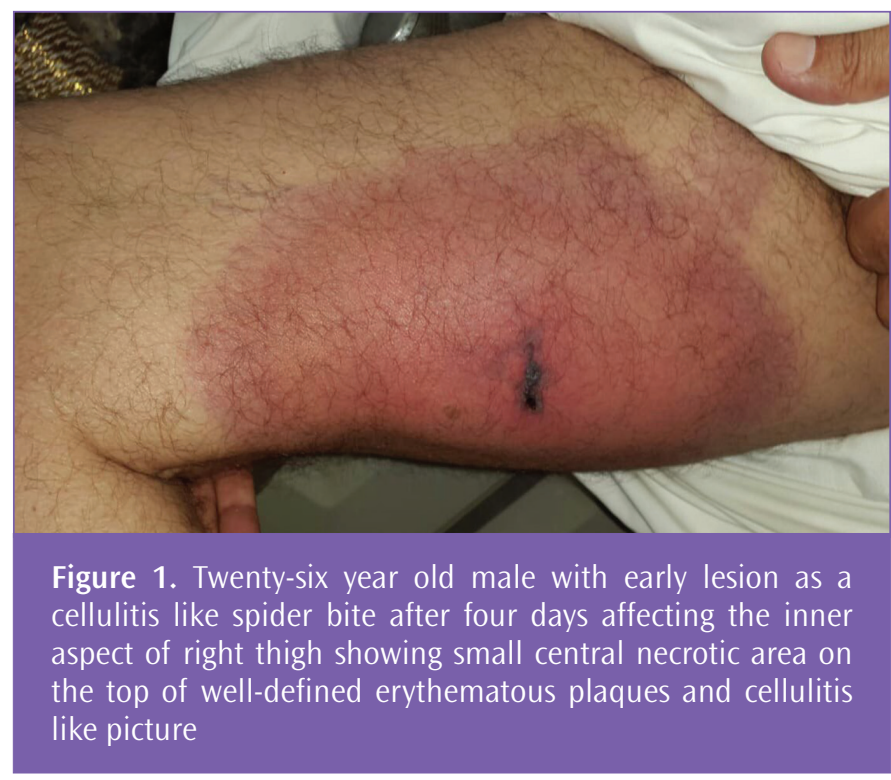


Hence this is the first study documenting the skin manifestation of spider bites in Iraq. The present work showed that the thigh with groin was the most common site (58.3\%) involved by spider bites, similar to other researchs $[19,20,26]$ followed, three $(12.5 \%)$ legs, three fingers (12.5) and three (12.5\%) male genitalia and one (4.16\%) was left axilla. Regarding male genitalia involvement by spider bites, an unusual finding of the present work where there is necrotic ulcer with black eschar affecting the glans penis which is not reported by previous studies.

These bites were commonly seen among males (79\%) as seen in the present work and this could be due to pastoral setting and wearing opened clothes so called (Dishdasha) and also happening of spider bites in summer time.

The most important features that differentiate spider bite ulcer from ordinary pyoderma gangrenosum:

(a) The presence of black eschar which resulted from gangrenous tissue caused by spider toxin.

(b) Polygonal border due to uneven distribution of toxin and its effect on the tissues and as venom spread gravitationally.

(c) Sex and site: in the present work most cases were among males and areas of predilection were upper thigh, groin and genitalia.

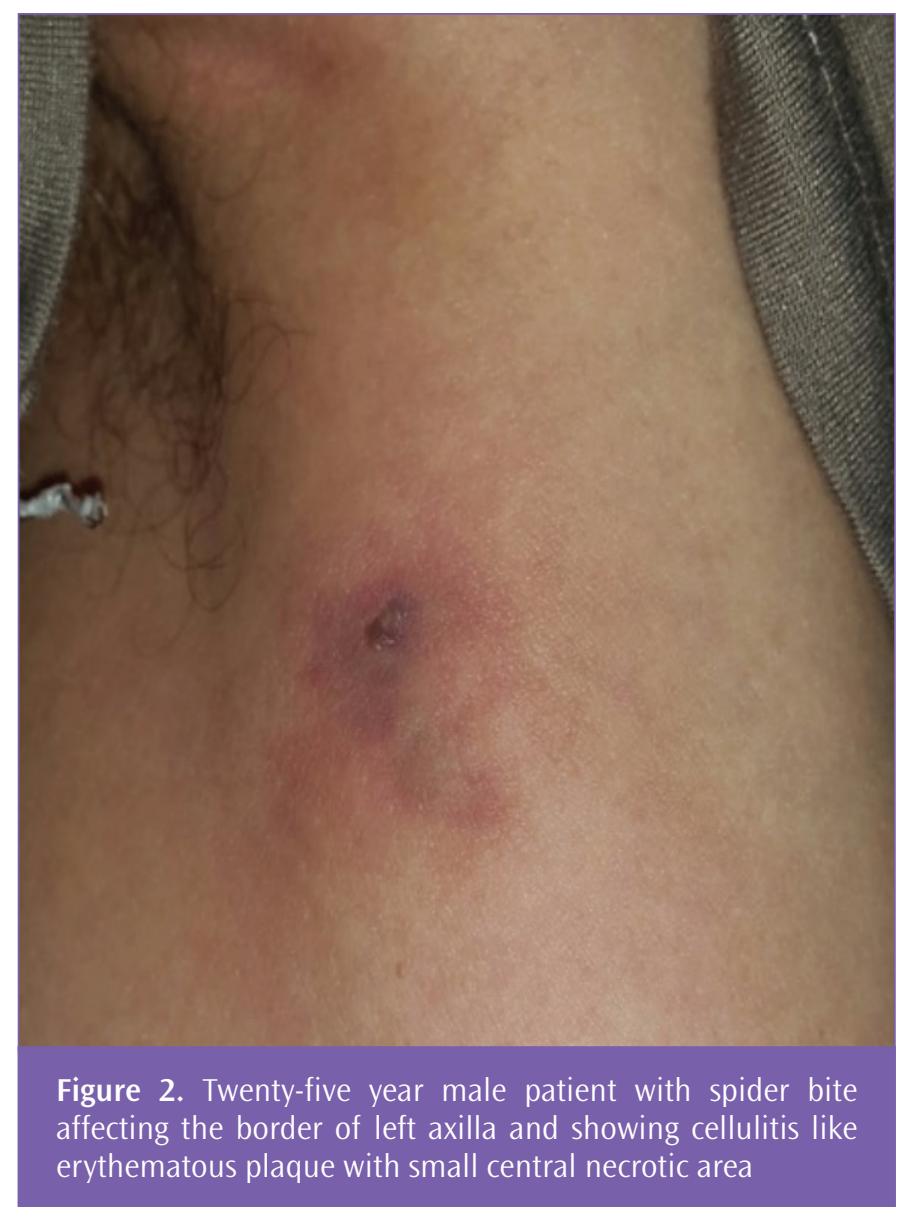

The presence of black gangrenous area at the center of cellulitis like lesion due to spider bite which is most important diagnostic feature to differentiate cellulitis like due to spider bite from ordinary bacterial cellulitis.

Medical therapy as a conservative regime was applied in the present work and this in agreement with other study as they found that surgical and debridement was not carried out mainly as controlled trials have found that early surgical intervention should not be carried out [27] as surgery increases local inflammation and potentiating toxin effects, in addition, wound chronicity, repeated graft rejection, and pyoderma gangrenosum may result $[22,27]$.

Although spider bites are rare but should be always remembered whenever we see red plaque with central necrosis or polygonal ulcer that covered with black eschar to avoid wrong diagnosis and mismanagement.

To the best of our knowledge this is the first clinical study describing spider bites in such clinical details.

\section{Study Limitations}

Histopathology was not carried out for any patient, as biopsy was refused by patients. In addition, the biopsy may exacerbate the acute condition of the spider bite ulcer.

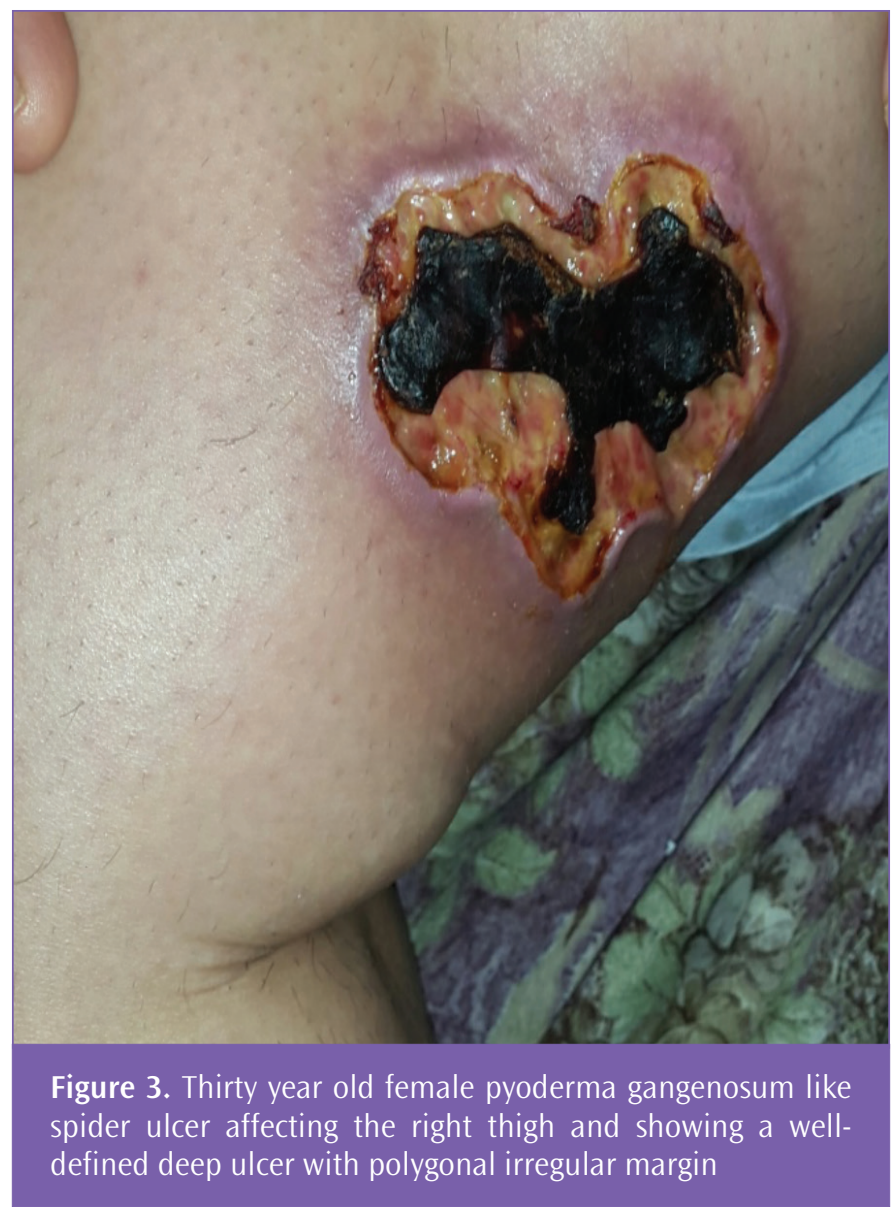




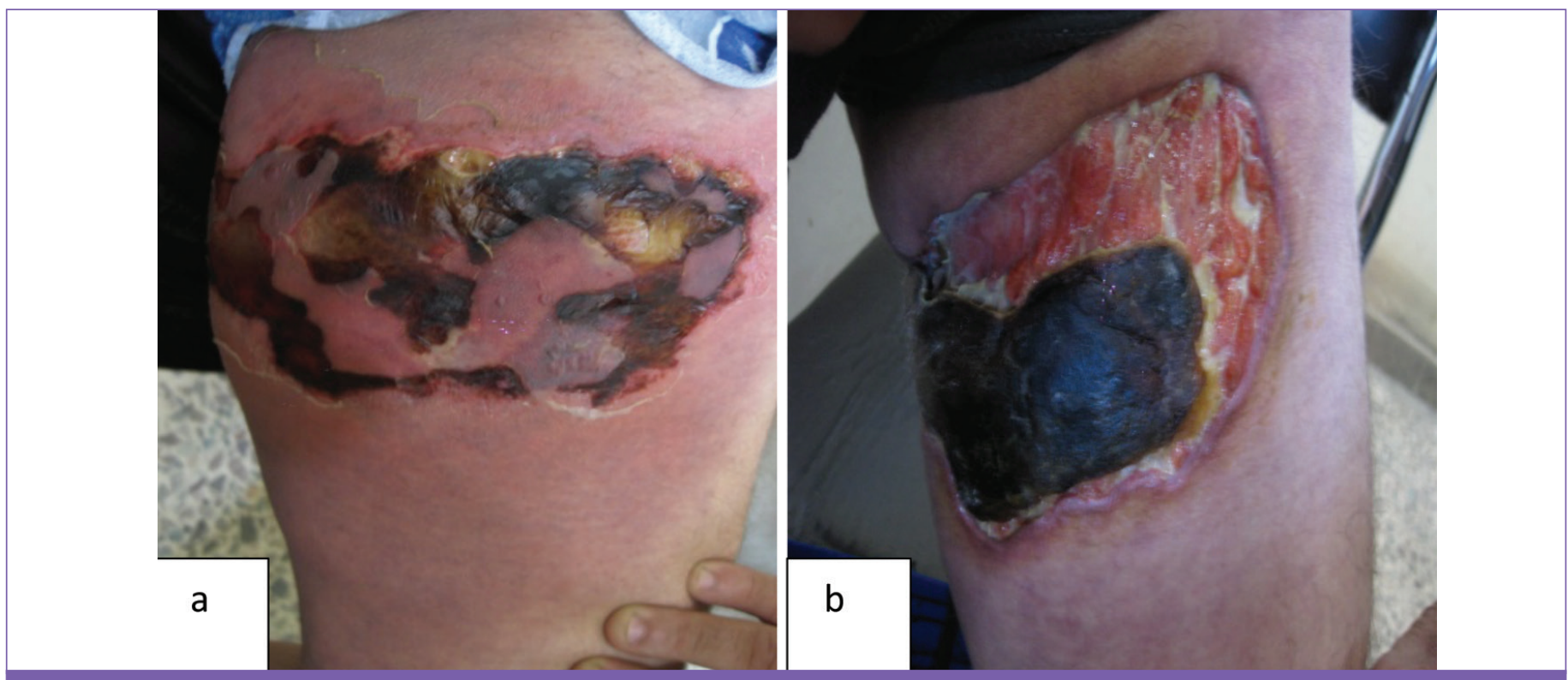

Figure 4. Thirty-one year old male with spider showing pyoderma gangrenosum like after ten days (a) and after three weeks (b) following therapy

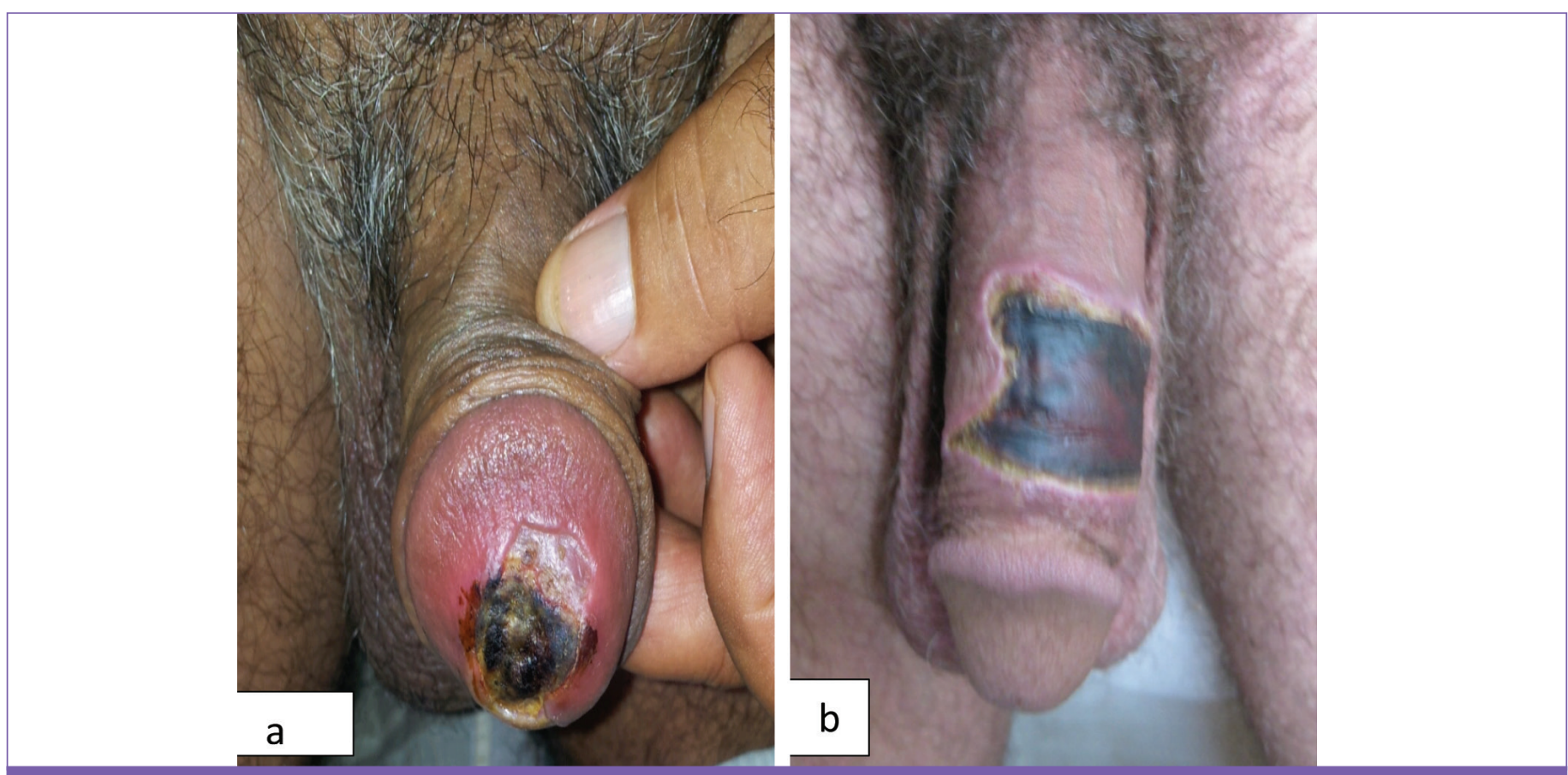

Figure 5. a, b) Spider bites in two males showing pyoderma gangrenosum like ulcers of penis with polygonal margin with thick eschars

\section{Conclusion}

Spider bites might be presented as early cellulitis like and late pyoderma gangrenosum like. The commonest sites affected were lower limbs, most commonly thighs and male genitalia. Healing might take several weeks to several months depending on the size of necrotic ulcer.
Wound debridement was not carried out as surgery increases local inflammation and potentiating toxin effects, wound chronicity, repeated graft rejection, and pyoderma gangrenosum may result. Skin grafting might be suggested for large ulcer as to dcrease the time of morbidity and recovery. 


\section{Ethics}

Ethics Committee Approval: As this study was carried out since the last nine years and it is mainly case series descriptive study rather than therapeutic, hence we do not think to have ethical approval.

Informed Consent: Written permission was taken from each patient before photograph and after explaining to the patient about the nature of the disease and aim of the study.

Peer-review: Internally peer-reviewed.

\section{Authorship Contributions}

Surgical and Medical Practices: K.E.S., R.I.J., Concept: K.E.S., R.I.J., Design: K.E.S., R.I.J., Data Collection or Processing: K.E.S., R.I.J., Analysis or Interpretation: K.E.S., R.I.J., Literature Search: K.E.S., R.I.J., Writing: K.E.S., R.I.J.

Conflict of Interest: No conflict of interest was declared by the authors.

Financial Disclosure: The authors declared that this study received no financial support.

\section{References}

1. Schwartz R A , Steen C J. Arthropod Bites and Stings. In : Kang S, Amagai M, Bruckner A L, Enk AH , Margolis DJ , McMichael AJ , Orringer JS, editors. Fitzpatrick's Dermatology in General Medicine, 9th ed. New York: McGrow Hill; 2019. p. 3324-3328.

2. Diaz JH, Leblanc KE. Common spider bites. Am Fam Physician 2007;75:869873.

3. Braitberg G, Segal L. Spider bites: assessment and management. Aust Fam Physician 2009;38:862-867.

4. Tintinalli JE, Stapczynski JS, Ma OJ, Cline D, Cydulka R, Meckler G. Tintinalli's emergency medicine: a comprehensive study guide,7th ed. McGraw-Hill Medical; 2011. p. 1344-1354.

5. Shlamovitz GZ. Man With Back Pain. Black window spider bite. Ann Emerg Med 2011;58:496-500

6. Nordt SP, Clark RF, Lee A, Berk K, Lee Cantrell F. Examination of adverse events following black widow antivenom use in california. Clin Toxicol 2012;50:7073.

7. Garcia H, Tanowitz H, Del Brutto O. Neurological effects of venomous bites and stings: snakes, spiders, and scorpions. Neuroparasitology and Tropical Neurology: Handbook of Clinical Neurology Series (Editors: Aminoff, Boller, Swaab) 2013;114:349-368

8. Al-Iraqi RA, Nayef NS. New Record of Two Species of Black Widow Spider in Mosul City (Iraq). Rafidain Journal of Science 2014;25:17-25.

9. Abdul-Rassoul MS, Al-Jalely BH, Al-Nuaimi KT, Al-Ani LK. First record of red-back spider Latrodectus scelio Thorell, 1870 (Araneae: Theridiidae) in Baghdad, IRAQ. Bull Iraq Nat Hist Mus 2012;12:1-5.
10. Gertsch WJ, Muliak S. Loxosceles reclusus. Bull Am Mus Nat Hist 1940;77:317.

11. Horner NV, Stewart KW. Life history of the brown spider, Loxosceles reclusa Gertsch and Muliak. Texas J Sci 1967;19:333-347.

12. https://www.brownreclusespider.org/camel-spider/camel-spider-in-iraq.htm

13. Heitz JR, Norment BR. Characteristics of an alkaline phosphatase activity in brown recluse venom. Toxicon 1974;12:181-187.

14. Wright RP, Elgert KD, Campbell BJ, Barrett JT. Enzymatic characterization of Missouri brown spider venom. Arch Biochem Biophys 1973;159:415-426.

15. Kurpiewski G, Forrester LJ, Burrett JT, Campbell BJ. Platelet aggregation and sphingomyelinase $D$ activity of purified toxin from the venom of Loxosceles reclusa. Biochem Biophys Acta 1981;678:467-476.

16. Dillaha CJ, Jansen GT, Honeycutt WM, Hayden CR. North American loxoscelism: necrotic bite of the brown recluse spider. JAMA 1964;188:33-36.

17. Rekow MA, Civello DJ, Geren CR. Enzymatic and hemolytic properties of brown recluse spider (Loxosceles reclusa) toxin and extracts of venom apparatus, cephalothorax and abdomen. Toxicon 1983;21:441-444.

18. Monsel G, Delaunay P, Chosidow O. Arthropods. In: Griffiths C, Barker J, Bleiker T, Chalmers R, Creamer D, editors. Rook's Textbook of Dermatology, 9th ed. Singapore: Blackwell Science; 2016. p. 32-34.

19. Gremski LH, Trevisan-Silva D, Ferrer VP, Matsubara FH, Meissner GO, Wille AC, Vuitika L, Dias-Lopes C, Ullah A, de Moraes FR, Chávez-Olórtegui C, Barbaro KC, Murakami MT, Arni RK, Senff-Ribeiro A, Chaim OM, Veiga SS. Recent advances in the understanding of brown spider venoms: from the biology of spiders to the molecular mechanisms of toxins. Toxicon 2014;83:91-120.

20. Dyachenko P, Ziv M, Rozenman D. Epidemiological and clinical manifestations of patients hospitalized with brown recluse spider bite. J Eur Acad Dermatol Venereol 2006;20:1121-1125.

21. Swanson DL, Vetter RS. Bites of brown recluse spiders and suspected necrotic arachnidism. N Engl J Med 2005;352:700-707.

22. Rees RS, Fields JP, King LE Jr. Do brown recluse spider bites induce pyoderma gangrenosum? South Med J 1985;78:283-287.

23. Sams HH, Mitchell WM, Stratton CW, King LE Jr. Culture and immunohistochemical evidence of Chlamydia pneumoniae infection in ulcerative pyoderma gangrenosum. J Am Acad Dermatol 2003;48:966-969.

24. Monte AA, Bucher-Bartelson B, Heard KJ. A US perspective of symptomatic Latrodectus spp. envenomation and treatment: a national poison data system review. Ann Pharmacother 2011;45:1491-1498.

25. Zamani A, El-Hennawy H. Preliminary List of the spiders of Iraq (Arachnida: Aranea). ARACHNIDA Rivista Aracnologica Italiana 2016;4:12-20.

26. Isbister GK, Gray MR. A prospective study of 750 definite spider bites, with expert spider identification. QJM 2002;95:723-731.

27. Rees RS, Altenbern DP, Lynch JB, King LE Jr. Brown recluse spider bites: a comparison of early surgical excision versus dapsone and delayed surgical excision. Ann Surg 1985;202:659-663. 